\section{Migrant Workers as Cultural Intermediaries}

\author{
Muna Yastuti Madrah ${ }^{1}$ and Suharko²
}

Komunitas: International Journal of Indonesian Society and Culture 11(1) (2019): 129-140

DOI:10.15294/komunitas.v11i1.18206

(C) 2019 Semarang State University, Indonesia p-ISSN 2086 - 5465 | e-ISSN 2460-7320

http://journal.unnes.ac.id/nju/index.php/komunitas

UNNES JOURNALS

${ }^{1}$ Faculty of Islamic Studies Universitas Islam Sultan Agung (UNISSULA)
${ }^{2}$ Departement of Sociology Universitas Gadjah Mada

Received: August 30, 2018; Accepted: March 1, 2018; Published: March 30, 2019

\begin{abstract}
This article aims at proposing an analysis formula on how the mechanism of cultural intermediaries done by Indonesian migrant worker student. The subject of this study were Indonesia migrant worker students in Korea undertaking higher education while under the contract as migrant workers. Various previous research on migrant workers mostly put them as "those who are powerless or unskilled." The emergence of these migrant worker students reflects that there is a change in values in viewing immaterial consumption by migrant workers. There is a kind of trendsetter (role model) that might influence them to enter the university as well as mediate new culture to other migrant workers. In this context, they are mediating the importance of having a higher education. Cultural intermediaries have an important role in creating a new social class. Many research reported those involved in the work of cultural intermediaries include music critics, fashion directors, bloggers, stylists, advertisers, brand agents- refer to a certain social class. However, there has not been much research on intermediary work carried out by migrant workers. This study conveys a new perspective placing migrant workers as actors involved in mediating "cultural products" and consumption of "tastes" of consumers
\end{abstract}

\title{
Keywords
}

cultural intermediaries; higher education; migrant workers

\section{INTRODUCTION}

This article will focus on the concept of cultural intermediaries and how its work. The term of cultural intermediary is related to Pierre Bourdieu and used by him to examine groups of workers involved in the supply of symbolic goods and services (Bourdieu, 1984). Bourdieu's most extensive reference to this group emerged in discussions about middlebrow culture in his work Distinction. Bourdieu's idea of cultural intermediaries was the term mobilization to allow changes in the structure of work in France in the 196os which saw the results of work that were educated and well-paid in both the public and private sectors (Nixon \& Gay,
2002). Bourdieu most strongly links the expansion of these new cultural groups and their increasing importance in the work structure with the bourgeoisie in the economic market sectors and the relationships associated with large media and broadcasting organizations.

According to Nixon and Du Gay, Bourdieu sees the emergence of new cultural intermediaries such as retooling the ethics of consumer capitalism and improving morality according to their duties. Following

\footnotetext{
Corresponding author

Jl. Kaligawe Raya KM. 4 Semarang City, Central Java, Indonesia

Email

munamadrah@unissula.ac.id; suharko@ugm.ac.id
} 
Bourdieu, these groups of workers can mobilize, from their relationships within cultural institutions, require specific educational assistance as forming tastes and triggers the disposition of new consumers. This article aims at explaining the possibility of placing Pekerja Migran Indonesia (PMI) - Indonesian Migrant Workers, as "agents" that build values on higher education, shape perceptions, build trends in higher education consumption among Indonesia's growing migrant workers. The phenomenon of Migrant Workers Students began to stick out since 2011 in several countries such as Malaysia, Singapore, Hong Kong, and Korea when Indonesian Open University is facilitating the Migrant Workers to continue their higher education (Padmo, 2015).

In many research, those involved in the work of cultural intermediaries include music critics, fashion directors, bloggers, stylists, advertisers, brand agents, and those show a particular class of work (Jennifer Smith Maguire \& Matthews, 2014), on the other hand, there has not been much research on intermediary work carried out by migrant workers. By observing more deeply at the daily lives of migrant workers in South Korea who choose to continue their studies, this study offers a new perspective on cultural intermediaries of Indonesian Migrant Workers. This article aims to describe the possibility of placing the migrant workers as an agent who builds value about higher education, shape perceptions, build up trends in the consumption of higher education among Indonesian migrant workers. Smith Maguire (Smith Maguire, 2014) sees that those involved in these cultural intermediaries works include music critics, fashion directors, bloggers, stylists, advertisers, brand agents, - professions which show a class of work. On the other hand, there have not been many studies on intermediary work carried out by migrant workers (industrial and domestic sectors).

Research on migrant workers has been widely carried out, both migrant workers in general and specifically those that examine female migrant workers. Some studies related to migrant workers include; research that focuses on gender relations and remittances (Rahman \& Fee, 2009), a redefinition of the existence of migrant workers (Astuti, 2005). Migrant workers are also always associated with marginalized groups. Ueno's findings reveal that migrant workers lose their values, tools, and meanings in managing their identities. Female migrant workers, really need an identity tool to look for values and meanings for their lives. Some female migrant workers have a strategy to restore their identity. Some are unsuccessful because of the restrictions inherent in any identity recovery effort (Ueno, 2010). Other research on migrant workers and gender is the low participation of female migrant workers in South Korea in migrant worker organizations (Lee, 2003). Lee said that there are very few non-profit organizations engaged in issues of female migrant workers in Korea, this is because the undocumented status of female migrant workers, especially those working in the entertainment sector, is largely undocumented, making it difficult for them to organize themselves.

This article deals with cultural intermediaries, where we try to analyze the position of migrant workers as cultural intermediaries. The study focused on migrant workers in Korea who continued their undergraduate studies when they worked in contracts as migrant workers. Cultural intermediary research offers an essential complement to the study of cultural production, where agency questions are usually focused on consumers, and questions about power in institutions. The concept of cultural intermediaries deliberately prioritizing agency, negotiation and power issues, moves the daily practice of market agents contested in the future to study cultural production (J. S. Maguire \& Matthews, 2012).

Cultural intermediaries are more than just forms of their job categories. Bourdieu shows that there is a close relationship between cultural intermediaries and habitus of individual practitioners, as well as those who practically have a cultural capital stock and subjective disposition. Bourdieu offers useful insights for the personal dynamics that underlie the reproduction of economic, cul- 
tural goods (the dynamics that are often lost when the focus is on macro and micro-scale conventions and structures be it institutional arrangements or market instruments). Bourdieu pays attention to the importance of class assessments in providing cultural intermediaries with the cultural capital and dispositions needed to complete their work. Cultural intermediaries depend on "good manners, good taste, or physical charm, familiarity with the dominant class culture and mastery of signs that symbolize differences and tastes, as well as the aesthetic dispositions and appropriate forms of selfpresentation. Such capabilities are primarily determined by the origin of the bourgeoisie and internalized as habitus (Bourdieu 1984 in (Smith Maguire, 2014)).

Bourdieu (1984: 359) describes cultural intermediaries as "little bourgeois class," or "knowledge class," which is involved with presentation and representation in providing symbolic goods and services. This little bourgeois was considered to belong to the bourgeoisie because they shared the same characteristics with the bourgeoisie, namely in terms of the desire to climb the social ladder. However, they are in the middle class, in the social sphere. Their practices of life are very directed, for example, they are very respectful of social order and very rigorous in terms of morals, highlighting desires or goodwill even though they are based on imitation of the culture of the dominant class (Haryatmoko, 2003).

According to Maguire, Bourdieu's discussion of the new petty bourgeoisie was developed further by paying attention to the disposition that channeled it into such work and gave them essential employment resources. In line with the class anxiety mentioned above, there is also a perceived harmony between personal taste, professional function, and position, which gives rise to a vocational mentality. Bourdieu uses literary critics as an example, by noting elective affinity between journalists, their articles and readers - in this case, cultural intermediaries are also their ideal consumers. Cultural intermediaries are also well-positioned to understand and direct the market (an es- sential source for flavor makers). Harmony between personal and professional produces dispositions that are fundamental to the influence of new symbolic and ethical positions. As a result, cultural intermediaries do not experience their work as necessary calculations, because this is an expression of their tastes and dispositions.

Concluding Bourdieu's conception, Maguire defines cultural intermediaries by looking at their role in mediating between production and consumption. They have extensive pedagogical functions, shape consumers' perceptions and preferences to mobilize their actions along the desired route. In this case, they have the effect of "symbolic imposition," framing certain cultural products, adding value as legitimate and, therefore, as valuable. They contribute to the production of the value of work or, how much is the same amount, about trusting the value of work (Jennifer Smith Maguire \& Matthews, 2010). The legitimate forms of culture do not require intervention in cultural intermediaries. Their cultural values are guaranteed through established hierarchies and authorities.

Conversely, cultural intermediaries work within the scope of legitimacy to canonize "the unauthorized" and therefore not monopolized by the dominant class (Bourdieu, 1984). They do this through the mobilization of established, legitimate cultures and the forms of media they have. Forming tastes and things that suit people requires cultural intermediaries to frame certain practices and products that are under the values they claim, which involve them in building a repertoire of cultural legitimacy (Jennifer Smith Maguire \& Matthews, 2014).

The terminology of cultural intermediaries has been interpreted in recent decades. Often overly framed as an entrepreneur's effort to maximize economic value, a package to broader social and moral political motivation. Cultural intermediaries are often seen as an attempt to characterize people who work in contemporary culture as dynamic, creative figures who seek new "practical utopia" through an innovative combination of economic and 
cultural practices (Banks: 2006 in Perry, Smith, \& Warren, 2015).

According to Florida in The Rise of Creative Class, as the main protagonist, cultural intermediaries are characterized by a free, creative spirit that is driven by the desire to make money and establish new relations between consumption and production (Florida, 2014) Florida gives a provocative new argument to think about why people live as they are and where they are going. Florida tracks the increasing role of creativity in the economy.

The role of cultural intermediaries continues to be a critical analytical focus for research on economics and society. Many researchers, provide analysis of the relationship between culture and economics by giving special attention to how different individuals and organizations mediate markets from production and consumption.

This concept continues to be developed by many scholars, for example, Du Gay(Du Gay, 1997) added that cultural intermediaries are symbolic experts who can influence the constitution in both the cultural production process and cultural consumption practices. Keith Negus, describing this group more broadly. According to him, they are regularly involved in forming connection points or articulations between production and consumption, and as social groups that obscure the difference between high art / popular culture, and the gap between personal taste and professional judgment, or leisure and work (Negus, 2002). Hutchinson simply explained that cultural intermediaries try to find creativity that emerges and makes certain types of cultural production accessible to a broader audience. They enable consumers and producers of cultural texts to engage in two-way dialogue: producers are faced with peripheral practices, and are very creative, by non-professional creative practitioners, while contributors are publicized to a broader audience (Hutchinson, 2017). Hutchinson describes the scheme of cultural intermediaries as follows:

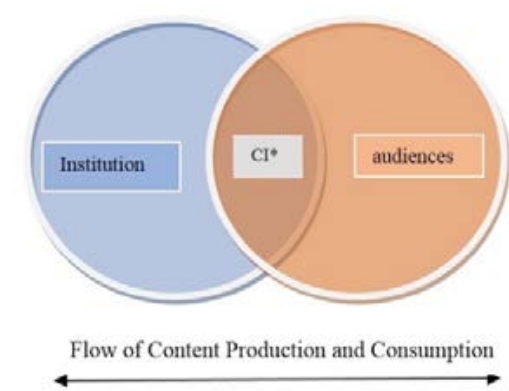

Figure 1. Sceme of cultural intermediaries according to Hutchinson (2017)

Cultural intermediaries are not monolithic workgroups, nor do they legitimize certain goods, services, and practices as they wish. They are very diverse in terms of their level of professionalism, other cultural and symbolic capital they have to influence the orientation of other actors and negotiate the influence of others. Besides, the items, services or behaviors they make, and the devices used to frame them, also vary, with each item and device carrying a degree of credibility and endurance that must still be there, which must be negotiated.

Therefore, research on cultural intermediaries has an impact on the formation of values for certain products of practice that offer a window for entering into construction contestation from cultural legitimacy more broadly. A research program that combines Bourdieu's attention with the production of boundaries between legitimate and illegitimate cultures, with new economic, sociological insights (J. S. Maguire \& Matthews, 2012).

With unauthorized surrounds with signs of authority and established credibility, cultural intermediaries help frame some of the more desirable choices. As such, they do not divulge a legal culture. However, it expanded the contents of the middle-style culture by popularizing it. Cultural intermediaries are not merely forming a sense and legitimate authority. This role involves cultural intermediaries in the long-term struggle for domination between different groups who struggle in part through the definition of "high taste" and relations that are following legitimate culture. A struggle that 
Bourdieu took from the 17th century into the mid-context 2oth century France, Bourdieu understands this struggle in terms of the fraction of the new class trying to establish their distance (work and generation), and the superiority of the established bourgeois pair and petty bourgeoisie, through their lifestyle and eating habits (Smith Maguire, 2014). This article would like to convey a new perspective by placing migrant workers as involved in mediating the production of "cultural products" and the consumption of "tastes" or consumer tastes which in Bourdieu's conception are referred to as cultural intermediaries.

\section{METHOD}

This article is based on research using a qualitative approach. Qualitative research emphasizes the nature of socially constructed reality, the close relationship between researchers and research subjects and the stresses of the situations that shape the investigation (Denzin \& Lincoln, 1994).

Research conducted in 2018 using critical ethnographic methods, to support the theoretical framework that has been built. Critical ethnography is a way to apply a subversive worldview to the logic of general cultural inquiry. Critical ethnography does not conflict with conventional ethnography. Critical ethnography offers a more direct style of thinking about the relationship between knowledge, society and political action. The central premise is that one can be scientific and critical, and the ethnographic description offers a powerful way to criticize culture and the role of research in it (Thomas, 1993). Practically, ethnography usually refers to forms of social research with some characteristics (Atkinson \& Hammersley, 1994) as follows:

- More emphasizes the exploration of the nature/nature of certain social phenomena, not testing the hypothesis of the phenomenon.

- More work with unstructured data or data that has not been formulated in the code as a set of categories that still accept opportunities for specific ana- lyzes.

- Research on a small number of cases, or maybe one case in detail.

- Analyze data which includes the interpretation of the meaning and function of various human actions explicitly as a product that generally takes forms of descriptions and verbal explanations without having to use too much analysis of quantification and statistics.

Ethnography used to study a culture that is intact in a group in the natural environment for a long time by collecting, especially observational data. The research process is flexible and develops contextually in response to the realities of life encountered in the field (Creswell, 2003).

We choose critical ethnographic strategies to see how Indonesian labor migrants are involved in intermediary cultural work and question the contradictions of neoliberal capitalism in class formation. Critical ethnography is a type of reflection that examines culture, knowledge, and action. Critical ethnography will broaden horizons, expand the ability of our experience to see, hear, and feel. This will deepen and sharpen ethical commitment by forcing us to develop and act on commitment values in the context of the political agenda. Critical ethnography describes, analyzes, and is open to hidden supervision, the center of strength, and assumptions that impede, suppress, and limit(Thomas, 1993). Using critical ethnography, we can see in more depth how migrant workers are involved in the formation of perceptions (higher education) as the consumption among them. In this case, how they are framing certain cultural products (education) are legitimate and how they contribute to the production of cultural values.

Critical ethnography is a style of analysis and discourse embedded in conventional ethnography. As a consequence, critical and conventional ethnographers have some fundamental characteristics. Among these are dependence on qualitative interpretations of data, core rules of methods and ethnographic analysis, adherence to symbolic 
interactionist paradigms, and preferences for developing grounded theories (Glaser \& Strauss, 1967 in Thomas 1993). Nevertheless, some characteristics distinguish each from the others. In conventional ethnography the most commonly refers to the tradition of cultural description and analysis that displays meaning by interpreting meaning. Critical ethnography refers to a reflective process for choosing between conceptual alternatives and making judgments of meaning and valuable methods laden with research, policy, and other forms of human activity. Conventional ethnography describes what it is; Critical ethnography asks what can happen (Thomas, 1993).

Critical ethnography is not just criticism or complaint from a situation that "in our opinion" is not appropriate, nor confusion of critical theory (related to the Frankfurt school), which is a theory of capitalist society. Critical ethnography is conventional ethnography with political goals. Critical ethnography is more than a study of marginalized groups that are oppressed. Critical ethnographers use their work to help emancipatory goals or to negate repressive influences that lead to unnecessary social domination of all groups. Emancipation refers to the process of separation from thinkers' ways of thinking or actions that limit perceptions and actions to realize alternative possibilities. Repression is a condition in which thoughts and actions are limited in a way that removes recognition of this alternative. Conventional ethnographers generally speak for their "field" with other researchers. Critical ethnographers, consistently, receive an additional research assignment to increase their voices to speak to audiences on their interests as a tool to empower them by giving more authority to the voice of the subject.

As a consequence, critical ethnography comes from an explicit framework by modifying awareness or asking for an invitation to act, trying to use knowledge for social change. Cultural studies on conventional ethnography aim to describe it; on critical ethnography do it to change it. Conventional ethnographers recognize the impossibility, even distrust, of research that is free from normative bias and other biases but believes that this bias must be suppressed. Critical ethnographers celebrate their normative and political position as a means of arousing social awareness and social change (Thomas, 1993).

\section{RESULT AND DISCUSSION}

This research has brought new horizons where research related to migrant workers can be seen with a different approach - increased interest in young migrant workers with different motivations than the previous generation. Not only motivated by high income but also with the opportunity to reach credentials. The increasing number of migrant workers taking undergraduate studies is also due to the massive factor of intermediary cultural work carried out by migrant workers themselves.

\section{Migrant Workers as Cultural Interme- diaries}

The increasing number of migrant workers interested in higher education due to the role of a trendsetter among migrant workers themselves. They can be considered as market participants who mediate the value of a cultural product for consumers, including the consumption of higher education, Bourdieu identified this as a cultural intermediary (Smith Maguire, 2014). Many researchers, provide analysis of the relationship between culture and economics by giving special attention to how markets from production and consumption are mediated (mediated) by different individuals and organizations. The intermediary cultural terminology introduced by Bourdieu as a criticism of the emergence of new mass media. In Bourdieu's thinking, there is a relation between production and consumption to the economy, politic, and culture. The terminology of cultural intermediary directly pays attention to the changes brought about by the growth of workers involved in the production and symbolic circulation and often different economic practices (Negus, 2002).

How is the role of the migrant wor- 
kers as an intermediary? Starting from just a study group, Indonesian migrant workers and students in Korea asked the Indonesian Open University (UT) to open a class for Indonesian Migrant Workers in Korea. The interest of workers to continue their studies is increasing, and this is an excellent market for education service providers. Besides the Cyber Hankuk University of Foreign Studies (CHUFs), a local Korean cyber university also recently offered an undergraduate credential to migrant workers. Intermediaries play an essential role, especially with the use of technology, the movement of intermediaries is increasingly free, through space and time, and even influences the decisions of destination countries for prospective migrant workers.

The Indonesia migrant workers students understand how to build demand from the target consumers. They use their terms and languages. Migrant workers use the social and cultural capital that they have had before and when they become a student. Then the phrase "from us for us" is often reproduced to frame their mediation work. The most active group of student workers doing this kind of work is the Student Executive Body (BEM), even though any possibility that other migrant workers non-BEM member are also active in carrying out cultural intermediaries work. As appropriate, a tertiary institution both UT and CHUFs recruits students to become part of a team of cultural intermediaries. Although they are voluntary, they are very active and effective in carrying out the mediation and organizing work of students. Provocative and creative content continues to be produced and socialized to the target market in various creative media.

When migrant workers decide to continue to higher education, they argue that this is an opportunity to break the chain of public view as the unskilled by entering the academic world. This is where the gap that cultural intermediaries enter empty spaces by placing migrant workers as a trendsetter, doing creative jobs, influencing others and building opinions.

The view of the importance of high- ly educated Indonesian migrant workers is more influenced by the views of educational fundamentalism as manifested in a strong belief that the level of welfare in the future depends on the level of education. This belief subsequently made education (including higher education) a commodity, resulting in the capitalization of education. The capitalization of education is not only spread and attached to almost all levels of society and is always exhaled as the lifestyle of modern people. As a modern lifestyle, symbols of higher education for migrant workers continue to be created. Migrant workers are common to activities such as seminars, student orientation, workshops, public lectures, student camps, etc., where these activities are initially closely related to student life in general.

Indonesia migrant worker students socialize through community-based hobbies and regional networks. There are 35 hobby and regional-based Indonesian migrant workers associations in Korea. Often Indonesian migrant worker students are also active in this organization. This organization becomes commonplace to include narratives about higher education in community activities and even religious activities (usually mosque activities). Sentences like the "importance of seeking knowledge," "the glory of the group with knowledge" continuously reproduce to sell higher education. The Indonesian migrant workers cultural intermediaries continue to produce symbols of higher education for migrant workers through creative ways both directly with community and religious activities for example by continuing to repeat the postulate proposition about the virtues of studying and increasing the degree of knowledgeable people through messages which were inserted into community recitation.

From these community's senior figures emerged, becoming role models for Indonesian migrant workers who had just come to Korea. The role of seniors is quite high in the selection of organizational affiliations including the decision to continue studies for the new migrant workers.

Currently, information about the op- 
portunity of the migrant worker students has widespread even before the departure of Indonesian migrant workers to Korea. In the information leaflet about the training center of Korean studies it was mentioned that besides being migrant workers, they would also have the opportunity to become scholars. The BNP2TKI (National Agency for the Placement and Protection of Indo- nesian overseas worker) do socialization and also seminars organized by the full migrant workers community. Information for Indonesian migrant workers candidates is also spread through social media, especially facebook, youtube, whatsapps, and Instagram. Further analysis of how Indonesian migrant worker students perform intermediary work can be seen in the following Table.

Table 1. Mechanism of Work of Cultural Intermediaries

\begin{tabular}{ll}
\hline \multicolumn{1}{c}{ Activities } & \multicolumn{1}{c}{ Practices } \\
\hline Framing & What can be used to frame: social media such as Facebook, \\
& WhatsApp, kakaotalk with photo content, exciting and cre- \\
& ative invitation sentences, also through good motivation by \\
& carrying out religious and regional sensitivity. Regular and in- \\
& tense socialization through Indonesian migrant workers net- \\
& works, social media, seminars, etc. \\
& Indonesia migrant workers Students with expertise: organiza- \\
& tion, visual communication, design, photography (obtained \\
& from experience while in high school, or after joining orga- \\
& nizations in Korea). Besides, Indonesia migrant workers also \\
& display forms of expression, sharing information as a persua- \\
& sive and educational tool using cultural symbols (such as ritu- \\
& als, habits, beliefs, and norms that become the background of \\
& target consumers)
\end{tabular}

The impact of the work of The decision to continue higher education for Korean miCultural Intermediaries grants.

The Indonesian migrant worker students as cultural intermediaries involved in the framing process of products, services, ideas, and behavior as legitimate and appropriate points for the intended recipient. The location of cultural intermediaries within a particular cultureand specific occupation on the commodity chain provides a series of separate opportunities and constraints. This analysis is used to dismantle the conditions and networks in which the framing process occurs. First, (but not only), in the case of the intended receiver (receiver). Literature about cultural intermediaries and in other discussions about active workers, much attention is only directed to end consumers as recipients and interactive services from cultural intermediaries (e.g., Hardt and Negri, 2004; Lazzarato, 1996; Witz et al., 2003 in Maguire 2012). Examples of such intermediaries - are directly involved in interacting with consumers' perceptions and attachments to goods - including retailers (Baker and Woo) and frontline service workers (Jennifer Smith Maguire \& Matthews, 2014). It is also important to note that Indonesian migrant workers cultural intermediaries are involved in storytelling connected to audience's emotionality as migrant workers, they also use symbolic representations both historically and socially, and communicate their extraordinary experiences and bring those experiences to life.

What did the Indonesian migrant workers cultural intermediaries do? They build value, by framing how other people - end consumers, as well as other market players, including other cultural intermediaries - to involved with goods, influencing the orientation of others to these items as legitimate goods. "Goods" intended to include physical products and services, ideas and behavior. In the struggle to influence the perceptions and attachments of others, cultural inter- 
mediaries are distinguished based on their explicit claims to professional expertise in taste and value in specific cultural fields.

Let us look at it by using the concept of cultural circuits that provide a logical framework for the work of Indonesian migrant workers cultural intermediaries. Using this concept, we can see the process of production of meaning involving Indonesia migrant worker students which are shaped by many actors and influencing factors. These factors include organizations, audiences that interact with Indonesian migrant worker students, and also the environment and atmosphere in which Indonesia migrant worker cultural intermediaries are involved in the interaction. According to Curtin and Gaither (Curtin \& Gaither, 2007), cultural circuits can be seen in five schemes namely, production - representation - consumption - identity - regulation, which all collectively provides a shared cultural space. How Indonesian migrant workers cultural intermediaries move in cultural circuits can be described as follows:

- Production: The production moment gives Indonesian migrant workers the power to attach specific cultural meanings to a product or idea using language. They develop messages by selecting specific dictionaries and images that will resonate with the cultural context and experience of the target audience so that it can be more readily received.

- Representation: Indonesia migrant workers cultural intermediary's students represent the meaning of products and ideas (about higher education) by using various strategies such as preparing narratives to be published in various media, making posters and framing photos, making videos and organizing various activities, creating and managing websites. In advertisements, images and words are used together to communicate specific messages.

- Consumption: Indonesian migrant workers cultural intermediary students shape consumption by connec- ting new products and experiences with events or ideas that historically meaningful to their audience. They articulate meaning concerning cultural and social norms that circulate among audiences. Production and consumption are not in binary opposition to each other but exist as part of the intermediation chain because they are also both producer and consumers the message. Indonesia migrant workers use feedback from the public to allow producers to form their products, services and communication activities more precisely.

- Regulation: Curtin and Gaither explain the purpose of regulation here is about limitations. In the case of the migrant worker's context and their field of practice (i.e., organizational restrictions, budget constraints, technological infrastructure, traditional education systems, regulatory bodies, and legal controls or other cultural norms and expectations). Moment of regulation can be a barrier as well as facilitate them. For example, new technology can empower migrant workers by offering a means of communication that passes through the gates of traditional media. Furthermore, they also play a role in regulating attitudes, behaviors and policies both formally through public affairs and political lobbying as well as informally through corporate culture and culture of identity.

- Identity: refers to the meaning given to a particular object or group through the process of production and consumption and is inherently subjective. Goods, services, and ideas symbolically consume Indonesia migrant workers involved at this moment in three main ways, first, the production of organizational identity (UT or CHUFs), second, the construction of consumer identity; third, construction of audience identity through the practice of segmentation and targeting. As a cultural intermediary, Indonesian migrant worker identity is based on understanding the 
lifestyle of consumers with products (in this case higher education) to produce goods and experiences for consumers.

Many research on cultural intermediaries (Maguire 2008, Zukin \& Smith Maguire 2009, Woo 2012, Pitts 2015) always linkage on how the relationship between production and consumption as economic activity. The next question is, who will benefit from these cultural intermediaries works? In this context, it seems difficult to explain that Indonesian migrant works do cultural intermediaries' work will have a direct impact on economically because they do not directly serve certain products to be mediated. They mediated a value to become highly educated migrant workers with the glory of status as a migrant worker. This has an impact on increasing the number of workers who decide to continue their studies, and of course, universities as providers of educational services benefit from the exposure of more target consumers from individual classes. Then the position of the Indonesian migrant worker students as a cultural intermediary is actually on two legs. One as a chain of production machinery of capitalization of education on the other hand also as struggle as migrant workers identity.

It can be explained how Indonesian migrant workers cultural intermediary's positions in transforming economic capital into cultural capital. Bourdieu stated that only by learning, perseverance and hard work the lower class could do social mobility. In Bourdieu's view, cultural capital is an institutionalized competence or cultural knowledge in the form of educational qualifications. Education gives a person the capital of knowledge and competence needed to make a difference or estimated value. Education builds one's competence and knowledge which is used to give preference in thinking, behaving, acting in various ways (Haryatmoko, 2016) But whether social mobility happens to them, can be considered as a follow-up study.

Indonesian migrant workers in Korea occupy a low stratum position as holders of E-9 or E-10 visas (unskilled worker vi- sas). Even though this stratification and racial issue are not evident in daily life, these workers can always feel it, for example from the use of language, attitudes, and so on. Among the diaspora itself, this stratification continues to be reproduced (that the E9 and E1o visas are types of visas for unskilled workers). One method used to influence workers to take higher education is to say that with a diploma, workers can change the type of visa to a higher level, E7 (professional worker visa). Using an E7 visa, workers can bring their family (wife and child), choice a better job and maybe a better view from the Koreans.

However, the accumulation of cultural capital of the migrant worker students made them become the engine of cultural production from the capitalization of education through the work of cultural intermediaries. This seems to be a double standard of the face of capitalism.

\section{CONCLUSION}

This article focuses on how Indonesian migrant worker-student are seen as cultural intermediaries. This article explores how the status of migrant workers and cultural intermediaries continues to place it as a production machine for the capitalization of education. An open university system and an ICT-based education system have opened opportunities for migrant workers to enter the idealist world of higher academic education - a very contradictory to the world of migrant workers who tend to be pragmatic. ICT has also facilitated their work on how higher education becomes a regular consumption for migrant workers. Emerging views with the increasing number of working classes entering higher education can be interpreted as evidence of a decline in social-structural barriers in modern risk societies, or a reflective where individuals engage reflexively with their social environment and take strategic risks through decisions about the critical ways of life (Lehmann, 2009).

The credential is essential for one's competence. Formal education has been 
postulated by the economic debate of globalization and knowledge, which, according to Lehman as the elimination of structural barriers to educational attainment has become an essential aspect of modern society lately.

Even though university students from the working class face other structural challenges at the same time they build good advantages that help them overcome these shortcomings. That the advantage of proper construction is seen as something individualistic, not collective, is a significant difference, because in many research goal of working-class students is social mobility. However, will they immediately gain social mobility by the credential? We recommend further research. Also, in this study, there was a tendency to increase young migrant workers. It is open up opportunities and discussions about how this transformation takes place and what factors influence it, the youth migration agenda is unusual for the continuation of this study.

\section{ACKNOWLEDGMENTS}

This research can be done with financial support from LPDP and Universitas Gadjah Mada.

\section{REFERENCES}

Andrevski, H., \& Lyneham, S. (2014). Experiences of exploitation and human trafficking among a sample of Indonesian migrant domestic workers. Trends and Issues in Crime and Criminal Justice, (471), 1-10.

Aprilliana, D., \& Meydianawathi, L. G. (2011). FaktorFaktor yang Mempengaruhi Remitansi TKI Asal Bali di Amerika Serikat. E Journal EP Universitas Udayana, 2(8), 373-383.

Ardli Johan Kusuma; Michael Ryan York; Rizki Hari Wibowo. (2015). Violence against Indonesian Migrant Workers - A Causal Analysis. Journal Hubungan Internasional, 4(No.1, April), 47-57. https://doi.org/http://dx.doi.org/10.18196/ hi.2015.0065.47-57

Astuti, T. M. P. (2005). Redefinition of the Existence of Migrant Women The Case of Return Migrant in Godong, Grobogan, Central Java. Southeast Asia a Global Crossroads SEASREP 1oth Anniversary Conference, 18(3), 205-212.
Atkinson, P., \& Hammersley, M. (1994). Handbook of qualitative research. Handbook of Qualitative Research.

Bourdieu, P. (1984). Distinction: a social critique of the judgment of taste (Translation). Harvard University Press. https://doi.org/Article

Choi, J.-S., \& Choi, S. (2005). Social work intervention with migrant workers in South Korea: Micro and macro approaches. International Social Work, 48(5), 655-665. https://doi. org/10.1177/oo20872805055331

Creswell, J. (2003). Research Design. Sage Publication. https://doi.org/10.1017/CBO9781107415324.004

Curtin, P. A., \& Gaither, T. K. (2007). Global Public Relations and the Circuit of Culture. In International Public Relations: Negotiating Culture, Identity, and Power. https://doi.org/http:// dx.doi.org/10.4135/9781452224817

Denzin, N. K., \& Lincoln, Y. S. (1994). Handbook of qualitative research. Handbook of Qualitative Research (Vol. 1).

Erel, U. (2010). Migrating Cultural Capital : Bourdieu in Migration Studies Author ( $\mathrm{s}$ ): Umut Erel Published by Sage Publications, Ltd. Stable URL : http://www.jstor.org/stable/42857433 JSTOR is a not-for-profit service that helps scholars, researchers, and student. Sociology, Vol. 44, No. 4 (August 2010), Pp. 642-66o, 44(4), 642-66o.

Haryatmoko. (2016). Membongkar Rezim Kepastian : Pemikiran Kritis Post Strukturalis. Yogyakarta: Kanisius.

Hutchinson, J. (2017). Cultural Intermediaries : Audience Participation in Media Organisations. Palgrave Macmillan. https://doi.org/10.1007/9783-319-66287-9

Lee, H. K. (2003). Gender, migration and civil activism in South Korea. Asian and Pacific Migration Journal, 12(1-2), 127-154.

Lehmann, W. (2009). Becoming Middle Class : How Working-class University Students Draw and Transgress Moral Class Boundaries. Sociology, 43(4), 631-647.

Maguire, J. S. (2008). Hanging Out and the Mall The Production of a Teenage Social Space.

Maguire, J. S., \& Matthews, J. (2010). Cultural Intermediaries and the Media. Sociology Compass, 4(7), 405-416. https://doi.org/10.1111/j.17519020.2010.00285.x

Maguire, J. S., \& Matthews, J. (2012). Are we all cultural intermediaries now? An introduction to cultural intermediaries in context. European Journal of Cultural Studies, 15(5), 551-562. https:// doi.org/10.1177/1367549412445762

Maguire, J. S., \& Matthews, J. (Eds.). (2014). The Cultural Intermediaries Reader. Sage Publication.

Negus, K. (2002). The Work of Cultural Intermediaries and the Enduring Distance Between Production and Consumption. Cultural Studies, 16(4), 501-515. https://doi. org/10.1080/09502380210139089

Pitts, F. H. (2015). The cultural intermediaries reader. 
Cultural Trends, 24(4), 330-333. https://doi.or g/10.108o/09548963.2015.1106033

Ponorogo, K., \& Hamidah, C. (2016). Investasi Properti Sebagai Pilihan Keluarga TKI di Kecamatan Babadan Kab. Ponorogo. Universitas Muhammadyah Ponorogo.

Rahman, M. M., \& Fee, L. K. (2009). Gender and the Remittance Process. Asian Population Studies, 5(2), 103-125. https://doi. org/10.1080/17441730902992059

Smith Maguire, J. (2014). Bourdieu on Cultural Intermediaries. In The Cultural Intermediaries Reader.

Subadi, T. (2016). Migrant Workers Become In Malaysia: Village Strategies To Overcome Poverty And Cost Of Education, 36-45.
Thomas, J. (1993). Doing Critical Ethnography. California: Sage Publication.

Ueno, K. (2010). Identity Management among Indonesian and Filipina Migrant Domestic Workers in Singapore. International Journal of Japanese Sociology, 19(19), 82-97. https://doi. org/10.1111/j.1475-6781.2010.01128.x

Woo, B. (2012). Alpha nerds : Cultural intermediaries in a subcultural scene. European Journal of Cultural Studies, 15(5). https://doi. org/10.1177/1367549412445758

Zukin, S., \& Smith Maguire, J. (2009). Consumers and consumption. Annual Review of Sociology, 30(2004), 173-197. https://doi.org/10.1146/annurev.soc.30.012703.110553 